\title{
Idiopathic Congenital Non-Chylous Pleural Effusion in Neonate: A Case Report
}

\author{
Arezou Hemmati ${ }^{\mathrm{a}}$, Reza Arjmand ${ }^{\mathrm{a}, \mathrm{b}}$, Omid Safari ${ }^{\mathrm{a}}$
}

\begin{abstract}
Congenital isolated pleural effusion is a rare cause of respiratory distress in neonates. It is usually chylous. We report a rare case of nonchylous congenital idiopathic pleural effusion.
\end{abstract}

Keywords: Idiopathic neonatal pleural effusion; Neonate; Non-chylous

\section{Introduction}

Respiratory distress is a leading cause of neonatal mortality worldwide, such as hyaline membrane disease, transient tachypnea of new born and neonatal pneumonia, congenital diaphragmatic hernia and congenital cystic adenomatous malformation, metabolic disturbances, and congenital heart diseases [1]. Pleural effusion is rare, and early diagnosis of neonatal pleural effusion is important not only for lowering mortality and morbidity, but also because it has an excellent prognosis following timely diagnosis and treatment. Pleural effusions are rare in the neonate but may be associated to several clinical conditions [2]. Chylothorax is the most common cause of pleural effusion in neonatal period [1-3]. Here, we report a rare case of non-chylous congenital idiopathic pleural effusion.

\section{Case Report}

A full-term neonate, birth weight $3.3 \mathrm{~kg}$, appropriate for gestation, was born by emergency cesarean section done for maternal bleeding and abrobtioplacenta. Baby did not require resuscitation and the Apgar scores were 8 and 10 at 1 and 5 min,

Manuscript accepted for publication December 18, 2015

aDepartment of Pediatric, Shahid Bahonar Hospital, Alborz University of Medical Sciences, Karaj, Iran

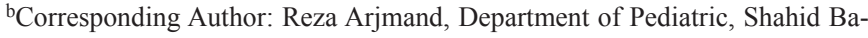
honar Hospital, Alborz University of Medical Sciences, Karaj, Iran.

Email: r.arjmand30@yahoo.com

doi: http://dx.doi.org/10.14740/jmc2397w respectively. He was admitted to the neonatal intensive care unit with a report of pleural effusion in prenatal sonography in last month of pregnancy. Respiratory rate (RR) was 66/min with mild subcostal retraction and breath sounds were diminished over the right hemithorax. There were no dysmorphic features and the baby was not hydropic. Rest of the systemic examination was normal. An arterial blood gas analysis was normal with $\mathrm{pH} 7.38, \mathrm{HCO}_{3} 18 \mathrm{mmol}$, and $\mathrm{PaO}_{2} 85 \mathrm{~mm} \mathrm{Hg}$. A portable chest X-ray done revealed white opacity in right side with shifting of airway and heart to the left side (Fig. 1). Chest ultrasound showed about $400 \mathrm{~mL}$ fluid in Rt hemithorax. A diagnostic tap was performed and $50 \mathrm{~mL}$ of straw colored fluid was aspirated and chest tube was inserted which drained $500 \mathrm{~mL}$ of straw colored fluid during 3 next days. Following pleural drainage, the infant improved remarkably. Repeat Xray chest showed full expansion of lungs at $24 \mathrm{~h}$ of age (Fig. 2 ). Feeding was initiated on day 2. The intercostal drain was removed on day 4 . The pleural fluid analysis showed transudate fluid containing protein $271 \mathrm{mg} / \mathrm{dL}$ and sugar $104 \mathrm{mg} /$ $\mathrm{dL}, \mathrm{Cl}-90 \mathrm{mEq} / \mathrm{L}$, triglycerides $74 \mathrm{mg} / \mathrm{dL}$, cholesterol $16 \mathrm{mg} /$ $\mathrm{dL}$, and leukocyte 1-2; no microorganisms were seen on gram staining and pleural fluid culture was sterile, indicative of nonchylous pleural effusion. Computed tomography (CT) of chest was normal. The sepsis screen was normal. USG of abdomen and skull were normal and baseline renal and liver function tests were within normal limits. The karyotyping of the infant was normal, i.e. 46, XY. A diagnosis of idiopathic unilateral non-chylous pleural effusion was made. The infant was started on feeds on day 2. There was not any change in color and appearance of effusion with feeding. He recovered fully with no recurrence of pleural effusion and was discharged on day 10 of life.

\section{Discussion}

Chylothorax or the accumulation of lymph fluid in the pleural cavity is the most common cause of clinically significant pleural effusion in neonates and can be congenital or acquired. Congenital chylothorax can be seen with multiple congenital malformations that result in poor development or obstruction of the lymph system [1].

Spontaneous or idiopathic neonatal pleural effusion is defined as any effusion in a newborn of age less than 30 days, 


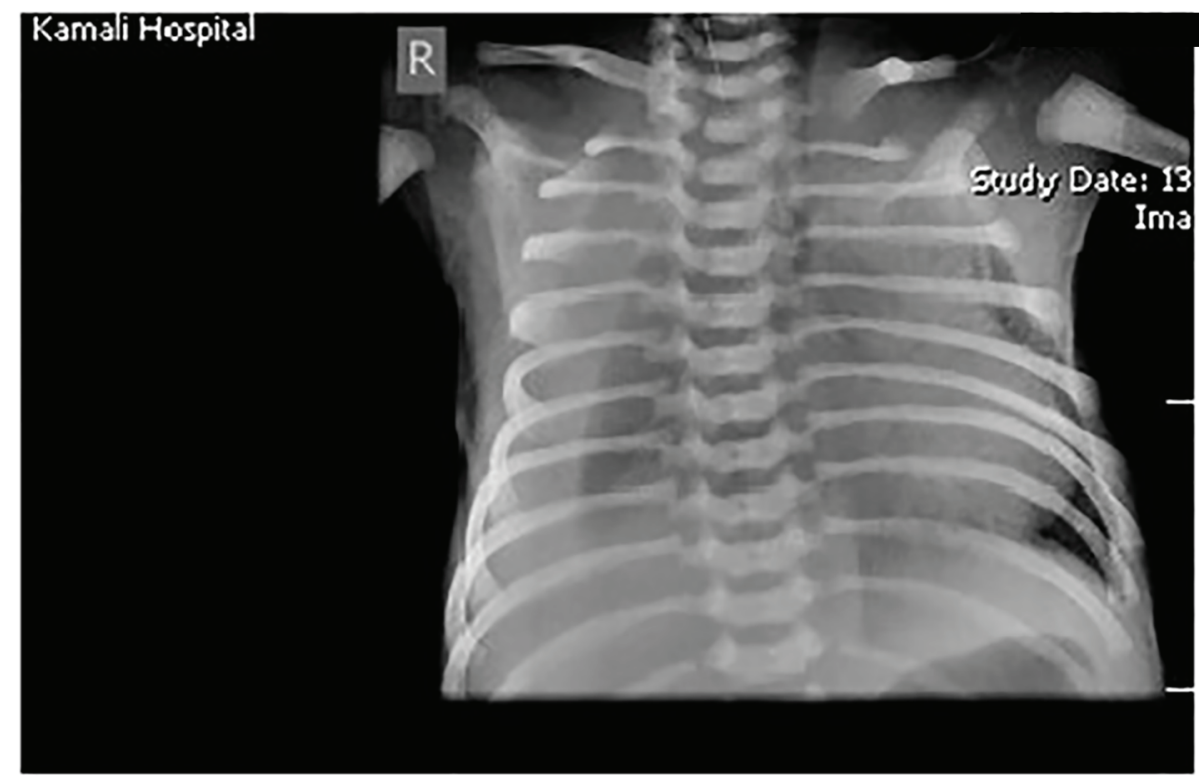

Figure 1. Pretreatment chest radiography showed white opacity in right hemithorax.

without any obvious etiology $[2,4]$. Causes of pleural effusion in the newborn include chylothorax, immune and no immune hydrops, Turner and Down syndromes, congenital pneumonia and congenital heart disease [5].

Idiopathic neonatal pleural effusion is frequently chylous in nature. Simple effusions are known to turn chylous after establishment of external fat feeds [3, 4]. However, in our case, the effusion remained non-chylous even after feeds were initi- ated. Chylous fluid is milky white in color with triglycerides more than $110 \mathrm{mg} / \mathrm{dL}$ (provided there is minimal fat intake), cholesterol between 65 and $220 \mathrm{mg} / \mathrm{dL}$ and leukocytosis with absolute cell count greater than $1,000 / \mu \mathrm{L}$ with a lymphocyte fraction greater than $80 \%$ [6].

Pleural effusion in the newborn frequently presents with respiratory distress and asphyxia ranging from mild to severe [3]. Early and active resuscitation with intubation and mechan-

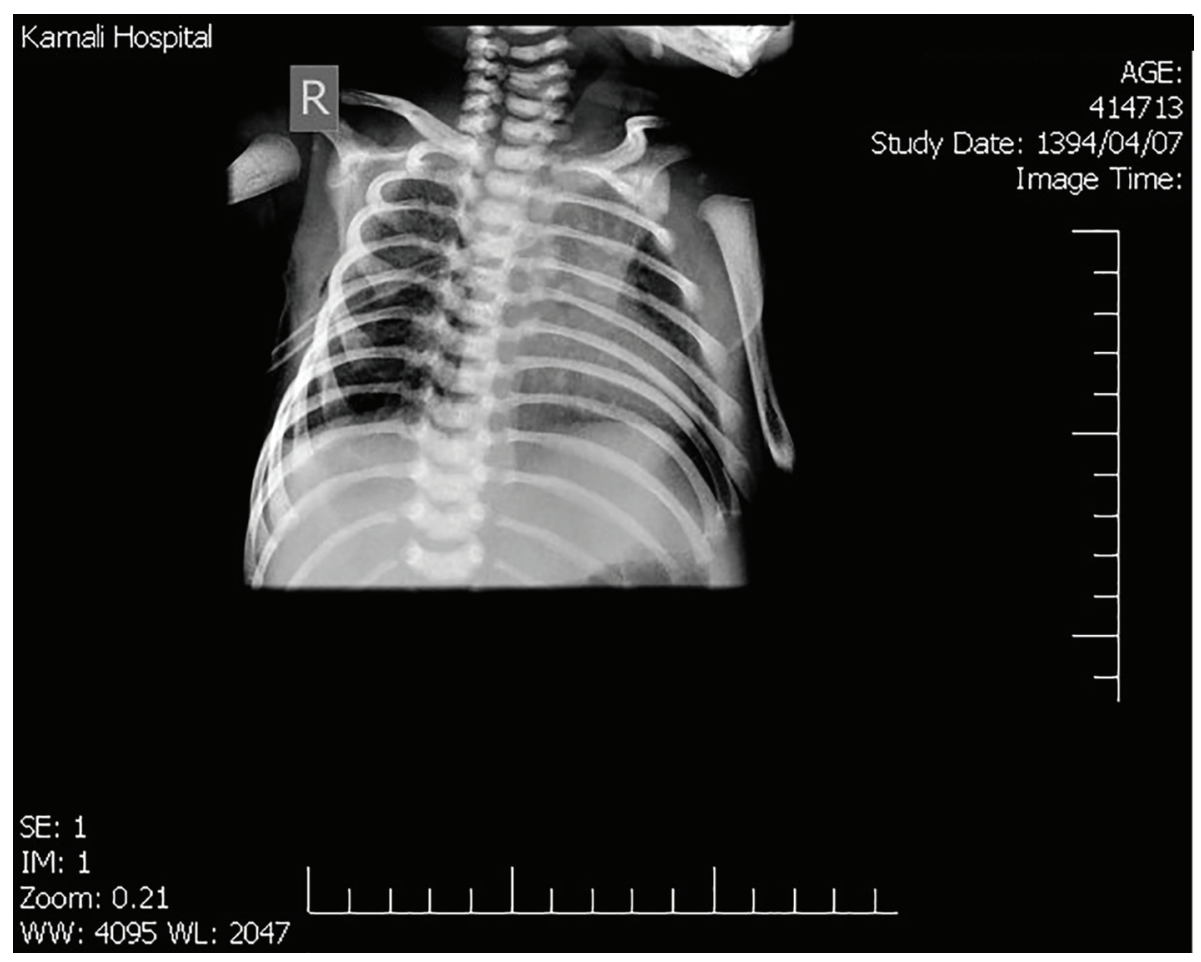

Figure 2. CXR after chest tube placement and fluid drainage. 
ical ventilation are needed to establish chest wall expansion [7].

Effusion presenting antenatally acts as a space-occupying lesion and restricts the development of the fetal lungs, which, as a result, may be hypoplastic. Polyhydramnios may result from interference with normal swallowing because of increased intrathoracic pressure [8]. Polyhydramnios was present in the index case but the lungs were normal.

\section{Conclusion}

Management includes thoracocentesis followed by intercostal drain insertion. Antibiotics should be given until an infectious etiology has been excluded [7,9]. Antenatally diagnosed pleural effusions, particularly if present prior to 32 weeks gestation, have a mortality rate as high as $55 \%[10,11]$. Bilateral pleural effusions are frequently associated with pulmonary hypoplasia. Postnatally, effusions persisting for more than 3 days increase the risk of chronic oxygen dependency [12].

\section{Grant Support}

None.

\section{Conflict of Interest}

The authors declare that they have no competing interests.

\section{References}

1. Moira A. Crowley. Neonatal Respiratory Disorders. Fa- nar off \& Martin's Neonatal-perinatal Medicine.10th edition. 2015.

2. Grover SB, Gupta P, Chellani H, Bharti LK, Vinayak R. Spontaneous neonatal pleural effusion. Indian J Radiol Imaging. 2007;17:71-73.

3. Wadhwa S, Verma M, Kaur J. Pleural effusion in neonatal period (a case report). Indian Pediatr. 1976;13(9):729731.

4. Depp DA, Atherton SO, McGough EC. Spontaneous neonatal pleural effusion. J Pediatr Surg. 1974;9(6):809-812.

5. Hansen TN, Corbet A, Ballard RA. Disorders of the chest wall, pleural cavity and diaphragm. In: Taeusch HW, Ballard AR, Gleason CA, editors. Avery's disease of the newborn. 8th ed. Philadelphia: Elsevier Saunders; 2005.

6. Hwang JY, Yoo JH, Suh JS, Rhee CS. Isolated non-chylous pleural effusion in two neonates. J Korean Med Sci. 2003;18(4):603-605.

7. Rocha G. Pleural effusions in the neonate. Curr Opin Pulm Med. 2007;13(4):305-311.

8. Greenough A, Roberton NR. Acute respiratory disease in the newborn. In: Rennie JM, Roberton NR, editors. Textbook of neonatalogy. 3rd ed. London: Churchill Livingstone; 1999.

9. Rocha G, Fernandes P, Rocha P, Quintas C, Martins T, Proenca E. Pleural effusions in the neonate. Acta Paediatr. 2006;95(7):791-798.

10. Hagay Z, Reece A, Roberts A, Hobbins JC. Isolated fetal pleural effusion: a prenatal management dilemma. Obstet Gynecol. 1993;81(1):147-152.

11. Hidaka N, Chiba Y. Fetal hydrothorax resolving completely after a single thoracentesis: a report of 2 cases. J Reprod Med. 2007;52(9):843-848.

12. Long WA, Lawson EE, Harned HS, Jr., Kraybill EN. Pleural effusion in the first days of life: a prospective study. Am J Perinatol. 1984;1(2):190-194. 